\title{
Corrosion effects on pullout behavior of hooked steel fibers in self-compacting concrete
}

\author{
Cristina Frazão ${ }^{\mathrm{a}, *}$, Joaquim Barros ${ }^{\mathrm{a}}$, Aires Camões ${ }^{\mathrm{b}}$, Alexandra C. Alves ${ }^{\mathrm{c}}$, Luís Rocha ${ }^{\mathrm{d}}$ \\ a ISISE, Dept. of Civil Engineering, University of Minho, Campus de Azurém, Guimarães, Portugal \\ b CTAC, Dept. of Civil Engineering, University of Minho, Campus de Azurém, Guimarães, Portugal \\ c CMEMS, Center of MicroElectroMechanical Systems, University of Minho, Campus de Azurém, Guimarães, Portugal \\ d UNESP, Universidade Estadual Paulista, Faculdade de Ciências, Campus de Bauru, Bauru, SP, Brazil
}

\section{A R T I C L E I N F O}

\section{Article history:}

Received 6 January 2014

Accepted 8 September 2015

Available online 26 September 2015

\section{Keywords:}

Corrosion

Steel fibers

Cracked SFRSCC

Pullout behavior

\begin{abstract}
A B S T R A C T
Fiber reinforced concrete structures are subjected to chloride and carbonation penetration that could initiate corrosion of steel fibers, with eventual pernicious consequences in terms of structural and durability performance. Cracks in concrete are known to hasten initiation of steel corrosion in reinforced concrete structures. The investigation of the impact of cracks on the corrosion initiation and the associated interfacial damage between concrete and steel fibers is important for understanding the mechanical behavior of steel fiber reinforced concrete. In the present work, with the aim of studying the corrosion action on the mechanical behavior of cracked Steel Fiber Reinforced Self-Compacting Concrete (SFRSCC), an experimental program was performed to characterize the corrosion of hooked-end steel fibers and to assess the fiber pullout behavior in cracked concrete, previously subject to the action of corrosion by exposure to aggressive chloride environment.
\end{abstract}

(c) 2015 Elsevier Ltd. All rights reserved.

\section{Introduction}

Steel fibers have been successfully used in concrete to improve its mechanical properties, such as post-cracking load bearing capacity and energy absorption performance, and also limit the crack width, with beneficial consequences in terms of concrete durability [1-3]. An increase in the crack width promotes the concrete permeability, favoring the occurrence of corrosion of steel reinforcements [2]. However, the concrete permeability decreases significantly by increasing the fiber content due to the reduction of shrinkage cracks and the breaking of continuity of pores and inter-connectivity of porous channels by the fiber reinforcement mechanisms [4].

The insufficient knowledge on the deterioration mechanisms caused by fiber corrosion contributes for a conservative design approach, which limits the mobilization of the full potential of Steel Fiber Reinforced Concrete (SFRC) [5]. It is widely reported that in case of SFRC, steel fiber corrosion is much less severe as compared with steel rebar reinforcement of concrete structures [6-8]. Due to large surface area to volume ratio, steel fibers are more effectively protected by the lime rich

\footnotetext{
* Corresponding author. Tel.: + 351253510 200; fax: + 351253510217

E-mail addresses: frazao_cristina@hotmail.com (C. Frazão), barros@civil.uminho.pt (J. Barros), aires@civil.uminho.pt (A.Camões), alexandra@dem.uminho.pt (A.C. Alves), lrocha@fc.unesp.br (L. Rocha).

URLs: http://www.isise.net (C. Frazão), http://www.isise.net (J. Barros), http://www.civil.uminho.pt/c-tac (A. Camões), http://www.ct2m.uminho.pt (A.C. Alves), http://www.fc.unesp.br (L. Rocha).
}

layer than the large diameter bars used in conventional reinforced concrete. However, the corrosion of fibers can produce micro-spalling of concrete, as well as the reduction of the sectional area of the fibers that arise some concerns on the long term material and structural performances of SFRC structures [9].

The primary causes of corrosion are chloride-penetration, and the reduction of $\mathrm{pH}$ of the concrete matrix due to carbonation [10].

The chloride diffusivity depends of the concrete pore structure and all the factors that determine it, such as, mix design parameters (namely $\mathrm{W} / \mathrm{C}$ ratio, type and proportion of mineral admixtures and cement, etc.), compaction, curing, placing and presence of cracks [11]. Concerning SFRC literature is mainly focused on corrosion arising from cracking process $[9,12,13]$ since as long as the matrix retains its inherent alkalinity and remains uncracked, corrosion is almost restricted to the fibers at the surface [14]. There are three main consequences of corrosion in SFRC associated to the cracking process: 1 ) a decrease of the load carrying capacity and energy absorption performance of the SFRC element (more brittle behavior); 2) due to the rust formation from fiber corrosion process, fiber-paste friction can increase, enhancing the fiber pullout response, with beneficial effects in terms of load carrying capacity and energy absorption of the SFRC element; 3 ) if crack width is small enough that self-healing almost restores SFRC integrity, fiber corrosion has negligible influence in terms of structural and durability performance [9].

Carbonation penetration rate is determined by the permeability of the concrete and starts at the concrete surface and continues inwards, 
as long as there is enough carbon dioxide available. In practice it has been found that the carbonation front is stopped when it reaches the steel fiber by the large supply of the lime around the fiber. This fiber may lose its protective passivating layer in the longer term, but the fibers at deeper position remain free from corrosion [15].

In SFRC, fiber and matrix are bonded together through a weak interface, whose study is important for understanding the mechanical behavior of such cementitious composites [16]. Moreover, with the outcome of new cement-based materials with improved mechanical properties, such is the case of steel fiber reinforced self-compacting concrete (SFRSCC), the study of the fiber/matrix interface assumes a renewed interest [16].

In the present work, in order to characterize corrosion of steel fibers, experimental results of electrochemical tests and scanning electron microscopy (SEM) analysis are presented and discussed. To study the corrosion influence on the pullout force versus loaded end slip response of steel fibers embedded in cracked self-compacting concrete (SCC), an innovative and non-standard experimental procedure was developed. The methodology adopted and the experimental results are presented and discussed.

The present research is part of a project that aims to develop an integrated numerical model capable of simulating the behavior of SFRC structures considering the relevant nonlinear phenomena developed in this composite material, namely [17]: cracking in tension and inelastic deformation in compression of the matrix; fiber distribution and orientation considering the SFRC rheological properties, casting conditions and geometry of the element; fiber reinforcement mechanisms based on the force-slip relationship obtained in fiber pullout tests. The contribution of the present research under this framework is a better understanding of the corrosion mechanisms on the fiber pullout force-slip response, by proposing an innovative test setup for this purpose, deep observation and interpretation of the interface between fiber and surrounding paste when SFRC is submitted to environmental conditions that favor the occurrence of fiber corrosion, and the evaluation and analysis of the fiber-slip response under these circumstances.

\section{Pullout behavior of steel fibers in self-compacting concrete}

In SFRC of low fiber volume fraction, the main benefits of fibers are effective after matrix cracking has occurred, since fibers crossing the crack ensure a certain level of stress transfer between both faces of the crack, providing to the composite a residual strength, which magnitude depends on the fiber, matrix and fiber-matrix properties [16].

The introduction of steel fibers in fresh concrete promotes a disturbance in the distribution of coarse and sand aggregates, requiring a higher concentration of cement paste around the fibers to fill the created space (end wall) [18]. The interface transition zone (ITZ) in the vicinity of reinforcement is then dependent on several parameters, among them the binder nature, the presence of admixtures, the $\mathrm{W} / \mathrm{C}$ ratio, fiber type and the mode and time of mixing $[16,19]$.

For new concretes containing distinct improved cement matrices (with low $\mathrm{W} / \mathrm{C}$ ratio), e.g. SFRSCC, the ITZ properties are not yet fully ascertained and much less are the involved mechanisms understood [16]. These matrices are rather innovative, since for attaining selfcompacting requirements they have to fulfill high demands with regard of filling and passing ability, as well as segregation resistance [16]. In order to improve mechanical anchorage and adhesion with the concrete matrix, the shape of steel fibers can be designed with hooked-ends, completely corrugated or provided with end cones.

Fiber pullout tests, which measure the force required to pullout a fiber embedded in a matrix under uniaxial tension, are commonly used to investigate fiber/matrix bond behavior [20]. The pullout behavior of a hooked-end steel fiber is associated with three mechanisms: adhesion - existing as elastic shear bond at the fiber-matrix interface; friction - existing as a frictional shear bond which permits relative slips along the fiber-matrix interface once the adhesion bond is broken;

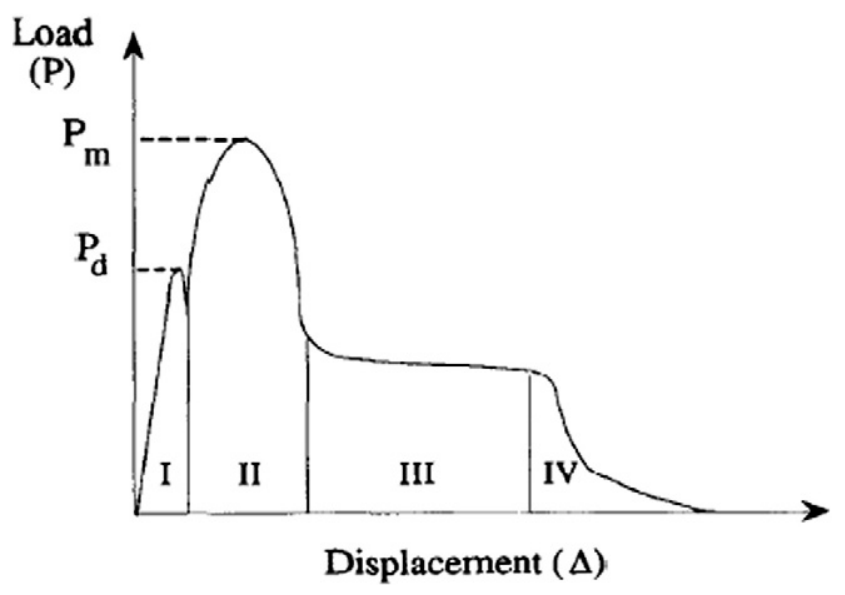

Fig. 1. Typical load-displacement curve of hooked-end fibers $\left(P_{m}-\right.$ maximum fiber pullout load; $P_{d}$ - maximum load of debond crack along the fiber/matrix interface) [21].

and mechanical anchorage that creates localized load transfer points between the fiber and matrix [20]. This analysis suggests that the pullout response of hooked-end fibers can be characterized by four distinct regions: Region I - an elastic response followed by de-bonding; Region II - fiber pullout and straightening - where the peak load occurs at a displacement corresponding to the length of the fiber deformation (i.e., approximately $4 \mathrm{~mm}$ for a hooked-end fiber), and corresponds to the end of the straightening process; Region III - frictional sliding of the partially bent fiber within the straight matrix duct; and Region IV - removal of the fiber from the matrix (Fig. 1) [21].

There is very little research work done on the behavior of the fiber itself under the influence of corrosion. The capabilities of the fibers are not yet completely understood, and the design of steel fibers is influenced rather by experience than by scientific knowledge. In this context, an experimental program was carried out in order to assess the fiber pullout behavior in cracked concrete, previously exposed to corrosive environment.

\section{Experimental investigation}

\subsection{Materials and mix composition}

In the current experimental program, one SCC mixture was produced, using CEM I 42.5R Portland cement (C), limestone filler (LF), fine river sand (FS) (maximum aggregate size of $1.19 \mathrm{~mm}$ and fineness modulus of 1.91), coarse river sand (CS) (maximum aggregate size of $4.76 \mathrm{~mm}$ and fineness modulus of 3.84) and crushed granite 5-12 mm (CA) (maximum aggregate size of $19.10 \mathrm{~mm}$ and fineness modulus of 6.64), water (W) and superplasticizer (SP) based on ether polycarboxylate (ViscoCrete 3005 ). Table 1 presents some physical characteristics of the cement and limestone filler.

Hooked-end steel fibers were used with a length $\left(I_{f}\right)$ of $60 \mathrm{~mm}$, a diameter $\left(d_{f}\right)$ of $0.90 \mathrm{~mm}$, an aspect ratio $\left(I_{f} / d_{f}\right)$ of 67 and a tensile yield stress of $1100 \mathrm{MPa}$.

The method used for defining the composition of the SCC, the mixing procedure and other properties of the SCC in the fresh state can be found elsewhere [22] and is based on packing density optimization. Table 2

Table 1

Physical characteristics of the cement and the limestone filler.

\begin{tabular}{lll}
\hline Physical characteristics & Cement & Limestone filler \\
\hline Specific weight $\left(\mathrm{kg} / \mathrm{m}^{3}\right)$ & 3150 & 2360 \\
Blaine specific surface $\left(\mathrm{m}^{2} / \mathrm{kg}\right)$ & 3873 & 3879 \\
Residue on $45 \mu \mathrm{m}$ sieve $(\%)$ & 2.00 & 77.18 \\
\hline
\end{tabular}


Table 2

Compositions for $1 \mathrm{~m}^{3}$ of concrete.

\begin{tabular}{|c|c|c|c|c|c|c|c|c|}
\hline & $\mathrm{C}(\mathrm{kg})$ & LF (kg) & $\mathrm{FS}(\mathrm{kg})$ & $\mathrm{CS}(\mathrm{kg})$ & $\mathrm{CA}(\mathrm{kg})$ & $\mathrm{W}(\mathrm{L})$ & $\mathrm{SP}(\mathrm{L})$ & $\mathrm{W} / \mathrm{C}$ \\
\hline SCC & 413 & 353 & 198 & 722 & 648 & 127.8 & 7.83 & 0.31 \\
\hline
\end{tabular}

includes the composition that has best fitted self-compacting requirements. In Table $2, \mathrm{~W} / \mathrm{C}$ is the water/cement ratio. Table 3 includes the fresh properties of SCC obtained.

To induce corrosion on steel fibers, a 3.5\% sodium chloride solution $(0.6 \mathrm{M})$ was used for steel fibers immersion.

\subsection{Characterization of fiber corrosion using electrochemical monitoring techniques}

Steel fibers corrosion displays itself most often in aqueous medium where the corrosive mechanism is essentially electrochemical. Electrochemical techniques can be used to assess, control and investigate the corrosion of steel fibers caused by corrosive attack of chloride ions. In the present work, the corrosion resistance of steel fibers was assessed through some electrochemical parameters, namely, open circuit potential, OCP, $\left(E_{O C P}\right)$, potentiodynamic polarization and linear polarization.

The $E_{O C P}$, which is the corrosion potential of the working electrode, was measured relative to a reference electrode since no potential or current is being applied to the cell. The steel fiber, in which potential was measured is called the working electrode. The ends of the working electrode and the reference electrode were connected directly to the terminals of one potentiostat in order to measure the corrosion potential. This method is characterized by monitoring the corrosion potential in relation to time permitting to know the open circuit potential and the time necessary for its stabilization.

A potentiodynamic polarization technique was used to generate polarization scan for obtaining polarization curves and provide continuous potential sweep at constant speed, starting with a potential where cathodic reactions predominate (lowest corrosion potential). The electrode potential was properly controlled with the potentiostat, which imposes to the electrode the desired potential relative to reference electrode and records the polarization current as a function of the potential. The current density, $i$, can be expressed as a function of the overpotential, $\eta$, where $\eta=E_{\text {applied }}-E_{O C P}$ is obtained from the Tafel equation:

$\eta=\beta \log \frac{i}{i_{0}}$

where $\beta$ is the Tafel slope, $i$ the applied current density, and $i_{0}$ the exchange current density [23]. The Tafel slope for the anodic and cathodic reactions occurring at open circuit may be obtained from the linear regions of the polarization curve, as illustrated in Fig. 2. Once these slopes were established, their interception provides the point of equivalent anodic and cathodic reaction rates (i.e., currents) [23]. The current density at that point is the corrosion current density $\left(i_{\text {corr }}\right)$ and the potential at which it falls is the corrosion potential $\left(E_{\text {corr }}\right)$ (Fig. 2). This test method is also useful to assess the polarization resistance, $R_{p}$ defined by the ratio of the applied potential to the applied current $(\Delta E / \Delta i)$ (remember Ohm's law: $V=I R$ ), Fig. 3. Polarization resistance measurements are an accurate and rapid way to measure the general corrosion rate. The

Table 3

Fresh properties of SCC

\begin{tabular}{lll}
\hline \multirow{2}{*}{ Concrete } & \multicolumn{2}{l}{ Slump flow } \\
\cline { 2 - 3 } & Spread $(\mathrm{mm})$ & $\mathrm{T}_{500}(\mathrm{~s})$ \\
\hline SCC & 731 & 8.3
\end{tabular}

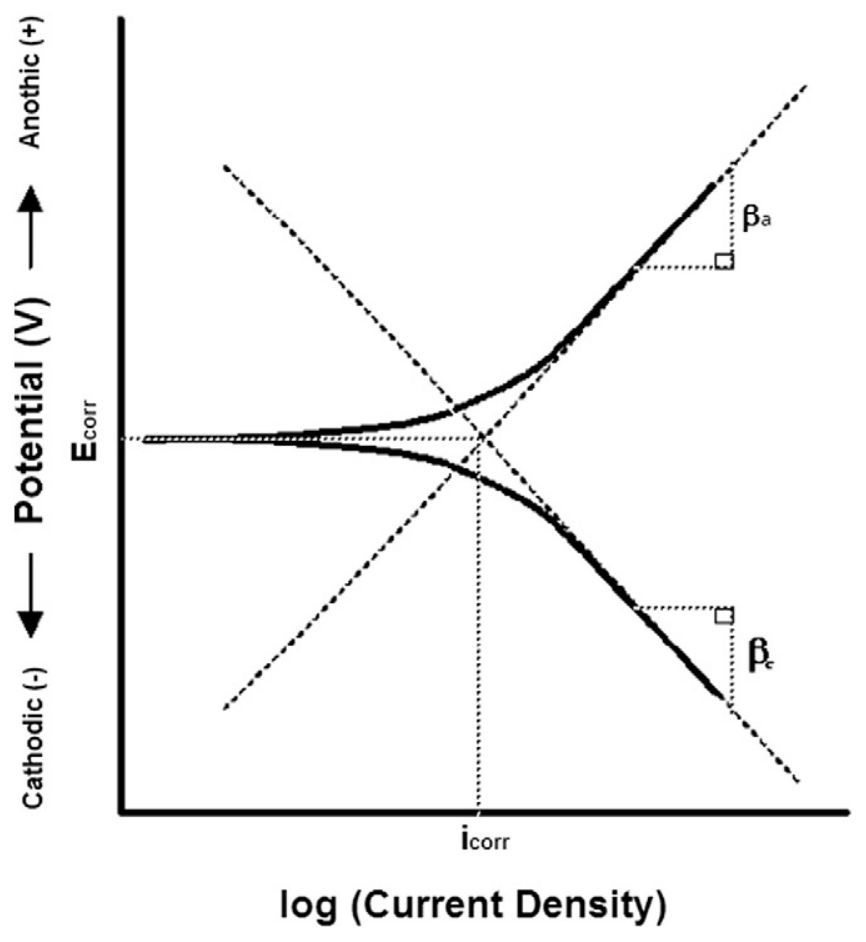

Fig. 2. Tafel slope calculation [23].

$R_{p}$ of a corroding electrode, defined from Eq. (2), corresponds to the slope of experimental curve $\Delta E$ vs. $\Delta i[24]$ :

$R_{p}=\left(\frac{\partial \Delta E}{\partial \Delta i}\right)_{\Delta i=0, d E / d t \rightarrow 0}$

The $R_{p}$ indicates the resistance to oxidation that a material exposed to an electrolyte offers when submitted to an external potential. Thus, a high value indicates that the material is more resistant to corrosion.

Linear polarization resistance was evaluated through a technique that is less intrusive than the previous one, due to a smaller magnitude of the applied potential. In this technique the potential was slowly scanned through a potential range until $30 \mathrm{mV}$ of the open circuit potential in order to obtain current responses more linear as possible (Fig. 3). The fundament of this technique is based on the work

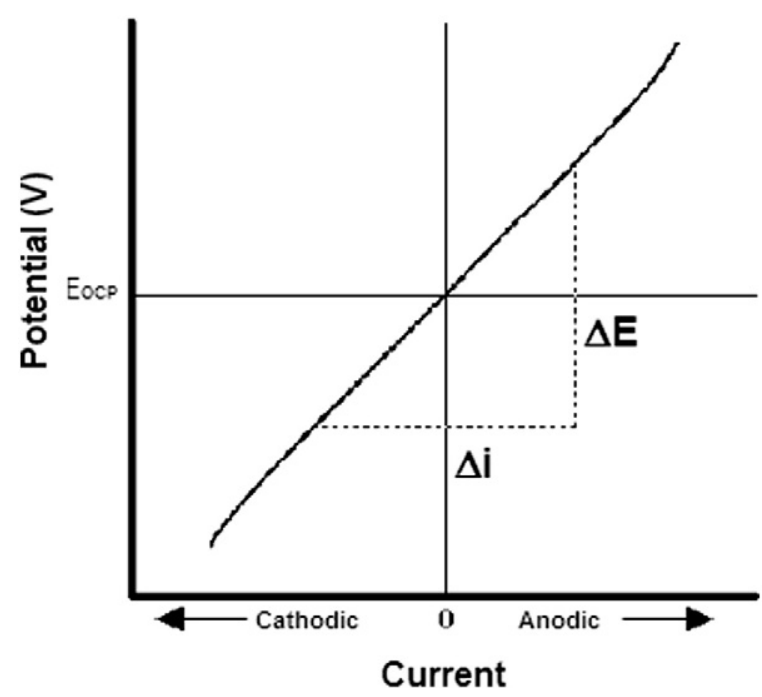

Fig. 3. Linear polarization resistance [23]. 
Table 4

Experimental program of electrochemical tests.

\begin{tabular}{lll}
\hline Tests & Procedure & Ambient temperature \\
\hline Series I & 1 hour of chloride immersion $\rightarrow \mathrm{OCP} \rightarrow$ potentiodynamic polarization & $(22 \pm 2)^{\circ} \mathrm{C}$ \\
Series II & 7 days of chloride immersion $\rightarrow$ weighing fibers & $(22 \pm 2)^{\circ} \mathrm{C}$ \\
Series III & 7 days of chloride immersion $\rightarrow \mathrm{OCP} \rightarrow$ potentiodynamic polarization & $(22 \pm 2)^{\circ} \mathrm{C}$ \\
Series IV & 30 min of chloride immersion $\rightarrow \mathrm{OCP} \rightarrow$ linear polarization & $(18 \pm 2)^{\circ} \mathrm{C}$ \\
Series V & 7 days of chloride immersion $\rightarrow \mathrm{OCP} \rightarrow$ linear polarization & $(19 \pm 2)^{\circ} \mathrm{C}$ \\
\hline
\end{tabular}

performed by Stern and Geary (1957), where an equation to determine the corrosion rate was proposed. This equation was derived by assuming the principle that around the corrosion potential, the anodic and cathodic portions of the total current in electrochemical system are equal, resulting in zero overall current. Applying small differences of potential around the corrosion potential and measuring the currents associated, it was possible to determine the linear polarization resistance $\left(R_{p}\right)$ of the electrode using Eq. (2) [25]. From this polarization resistance, the corrosion current, $i_{\text {corr }}$, may be calculated through the Stern-Geary equation:

$R_{p}=10^{6} \frac{\beta_{a} \beta_{c}}{2.303\left(i_{c o r r}\right)\left(\beta_{a}+\beta_{c}\right)}$

where $\beta_{a}$ and $\beta_{c}$ are the Tafel slopes illustrated in Fig. 2. It should be noted that a potentiodynamic scan, as discussed previously in this work, must be performed in addition in order to determine these slopes.

\subsubsection{Experimental setup}

To perform electrochemical tests on a particular steel fiber/solution system, an electrochemical cell was prepared. This cell contained the fiber to be investigated, the environment in which the tests were performed, as well as all of the implements required to conduct the measurement.

Prior to performing the tests, the fiber surface was prepared such that the initial condition of the measurement is well-defined and does not vary from test to test. In this context, the fibers were washed with distilled water and ultrasonic cleaning in propanol for $15 \mathrm{~min}$. This procedure aims to clean and decontaminate the surface of the fibers. The steel fibers were weighed before and after the execution of the tests in order to quantify the loss of fiber mass by corrosion during the electrochemical tests.

A sealant was applied (coating) on the fiber surface that was not in contact with the chloride solution (half length) in order to avoid that this zone of the fiber has been subjected to corrosion.

The electrochemical cell used had a standard three-electrode arrangement - the working electrode, the counter electrode and the reference electrode. The working electrode was the fiber being tested. The counter electrode was used to provide the applied current, and was composed of a highly corrosion resistant material (platinum). A saturated calomel electrode (SCE) was used as a reference electrode, which provided a stable reference for measuring accurately the applied potential to the working electrode. This electrode is a mercury one covered by a paste of $\mathrm{Hg}_{2} \mathrm{Cl}_{2}$, which is saturated with $\mathrm{KCl}$ and its potential with respect to the standard hydrogen electrode is equal to $+0.242 \mathrm{~V}$.

The equipment used for monitoring electrochemical tests was a potentiostat/galvanostat (Voltalab, Radiometer Analytical PGZ100), controlled by the software VoltaMaster-4 [26].

The five test series indicated in Table 4 were carried out. In each series four steel fibers were tested individually under the same conditions. Half-length of a fiber was immersed into a container with $150 \mathrm{ml}$ of $3.5 \%$ sodium chloride $(\mathrm{NaCl})$ solution. The $\mathrm{NaCl}$ concentration was chosen to reflect chloride concentrations that may be found under in-situ conditions.

In tests of series I, immediately after the immersion of the fibers in $\mathrm{NaCl}$ solution, the $E_{O C P}$ was recorded during $60 \mathrm{~min}$ before potentiodynamic polarization has been executed. This period of time was long enough for assuring steady state conditions for the corrosion potential.

In the potentiodynamic polarization tests, a continuous sweep and upward potential was executed from $-300 \mathrm{mV}$ below the value of $E_{O C P}$ up to $1000 \mathrm{mV}$, at a constant rate of $0.6 \mathrm{mV} / \mathrm{s}$. In order to achieve the desired degree of polarization, the potentiostat has measured and recorded the current applied to the working electrode. The potentiostat is then used to control the driving force (i.e., the potential) for electrochemical reactions by taking place on the working electrode. The magnitude of this driving force in turn dictates which electrochemical processes actually take place at the anode (metal oxidation) and cathode (reduction of an oxide or hydroxide present on the cathode surface). As a result, at the open circuit potential (potential at which the total anodic current is equivalent to the total cathodic current) the measured or applied current was zero.

The series II tests had the purposes of evaluating the weight loss that occurs in steel fiber by corrosion after immersion in $3.5 \% \mathrm{NaCl}$ solution for 7 days (Fig. 4). Thus, the steel fibers were weighed before and after the immersion period.

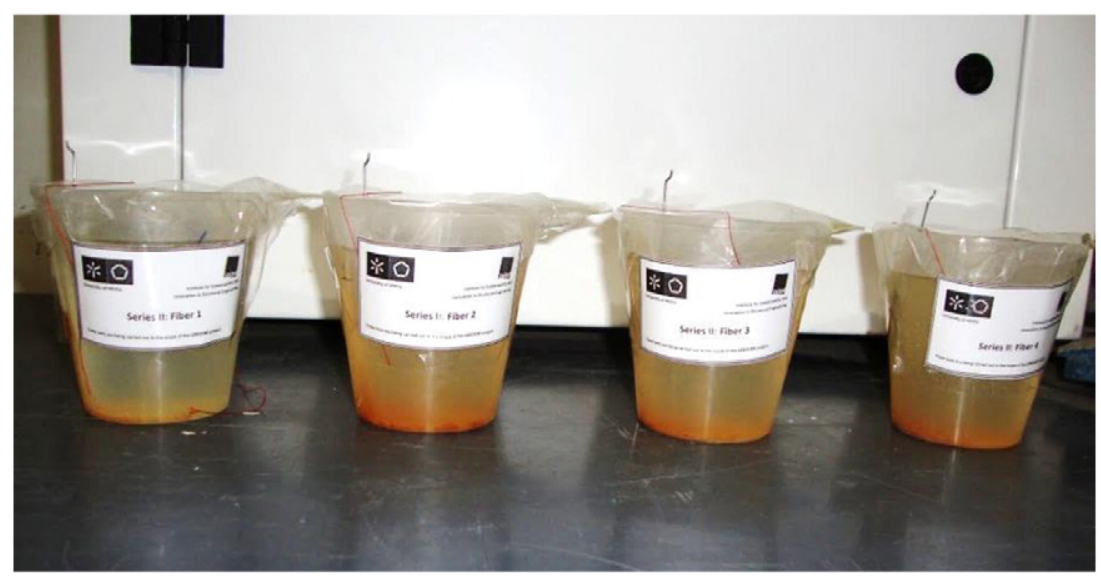

Fig. 4. Immersion of steel fiber in $3.5 \% \mathrm{NaCl}$ solution during 7 days. 
In series III tests, the $E_{O C P}$ was recorded for 30 min after the following periods of immersion: $0 \mathrm{~h}, 24 \mathrm{~h}, 48 \mathrm{~h}, 3$ days, 4 days and 7 days. After 7 days of immersion, potentiodynamic polarization tests were performed just as was done in series I.

In tests of series IV, immediately after the immersion of the fibers in solution, the $E_{O C P}$ was recorded for 30 min before performing linear polarization tests. In the linear polarization tests, a continuous sweep and upward potential of an amplitude of $\pm 30 \mathrm{mV}$ was executed in turn of the value of $E_{O C P}$, at a constant rate of $0.1 \mathrm{mV} / \mathrm{s}$.

In tests of series $\mathrm{V}$, the fibers were immersed in $3.5 \% \mathrm{NaCl}$ solution for 7 days and after this period linear polarization tests were performed by following the same procedure adopted in the tests for linear polarization of series IV.

\subsection{Fiber pullout tests under corrosive environment}

In order to investigate the corrosion effects of steel fibers on the fiber reinforcement mechanisms developed during the fiber pullout from an SCC medium, an innovative testing device was conceived, designed and built for the executing of non-standard experimental fiber pullout tests with steel fibers embedded in cracked specimens of SCC previously exposed to aggressive environment containing chlorides. This test aims to assess the effect of corrosion on the fiber/matrix bond behavior, by determining the fiber pullout load vs. slip response on a cracked specimen of SCC. This specimen, which has only one steel fiber embedded in the matrix that crosses the fracture surface, was subjected previously to immersion in a $3.5 \% \mathrm{NaCl}$ solution. The main parameters controlling the phenomenon of corrosion are the crack width and the critical concentration of chlorides required to initiate corrosion. At the material level, it is intended to investigate fiber corrosion for different crack widths of concrete and subjected to an aggressive environment containing chlorides. At the structural level, it is intended to assess the effect of fiber corrosion on the mechanical behavior of cracked SFRSCC, using a test for determining the pullout load versus slip response.

The influence of crack width, $w$, was investigated by adopting different crack width values for the samples, namely, $0.1 \mathrm{~mm}, 0.3 \mathrm{~mm}$ and $0.5 \mathrm{~mm}$. The study also considered reference samples with null crack width. The concrete cover thickness of the fiber, which is the distance from the fiber to the sample surface, was $10 \mathrm{~mm}$ (Fig. 5a).

An immersion period of the specimens of 10 days in $3.5 \% \mathrm{NaCl}$ solution was adopted in this test in order to induce corrosion in the fiber. Initially it was expected to perform wet/dry cycles of the specimens in the solution, but after preliminary tests, it was found that this cyclic conditions were too severe, leading to very intense corrosion of the fiber, causing a reduction of its cross-section and its consequent failure when submitted to pullout test.

The samples with non-null crack width were subjected to constant tension throughout the period of immersion, in order to simulate realistic conditions representative of a structural element of cracked SFRSCC under service loading conditions. The reference samples were immersed without any applied load, since in uncracked SFRSCC the mechanisms of fiber reinforcement are not mobilized. Each series of different crack width is composed of three specimens tested simultaneously under the same conditions.

Samples that were not subjected to chloride immersion were also part of this experimental program for comparison purposes. These samples, with the minimum adopted crack width (approximately $0.1 \mathrm{~mm}$ ), were kept in a lab environment and were not subjected to accelerated corrosion environmental conditions.

After the period of 10 days of immersion had ended, the fiber pullout tests were executed, even for those samples free from corrosion.

\subsubsection{Specimens fabrication}

For this test, cylindrical specimens with a diameter of $88 \mathrm{~mm}$ and a height of $160 \mathrm{~mm}$ were molded with just one steel fiber bridging the two parts that form this type of specimens (Fig. 5). The SCC composition
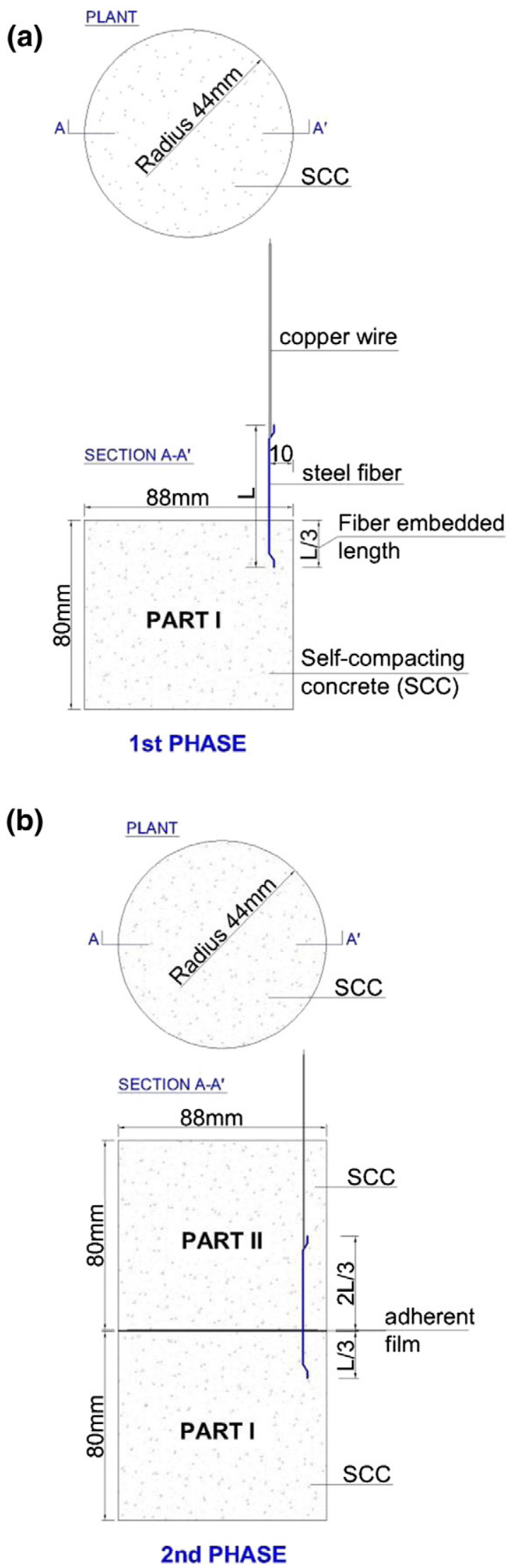

Fig. 5. Appearance of the specimen in the 1st phase (a) and in the 2nd phase (b). 
given in Table 2 was used to cast these specimens. The type of steel fibers used was the one presented in Section 3.1.

To create a specimen with a pseudo-crack, the two equal parts forming the specimen were molded in two phases, each one of $80 \mathrm{~mm}$ height casted with fresh SCC in each phase (Fig. 5). The fiber was embedded in the part of the specimen cast in the 1 st phase, with an embedment of about $1 / 3$ of its length. The remainder fiber's length was embedded in the other part of the specimen, cast in the 2nd phase. By assuring these two quite different fiber embedment lengths in the two parts of the specimen, it was assured that fiber pullout would always occur in the half part of the specimen with smaller embedment length (Fig. 5). Before casting the second part of the specimen (in the 2nd phase), an adherent polyethylene film with $0.2 \mu \mathrm{m}$ of thickness was applied on the top surface of the first part of the specimen (cast in the 1st phase) in order to prevent adhesion between the two parts of the specimen, and to materialize the surface for the propagation of the pseudo-crack bridged by the fiber (Fig. 5b). The crack width, $w$, will be therefore measured in this surface.

To monitor electrochemical fiber corrosion in the period of specimen immersion, a coated copper wire was welded to the steel fiber, with the region near the welding point sealed with beeswax (Fig. 5a). This coated copper wire has the other extremity outside the specimen and was sufficiently long to stay out of solution during the immersion period.

During the manufacture of the specimens, the positioning of the fiber was assured with the aid of an auxiliary structure consisting of two steel plates and three threaded rods which allow putting the fiber in the desired position, in terms of depth and concrete cover thickness.

In the 1st phase a PVC mold with $80 \mathrm{~mm}$ in height was used to cast the 1st part of the specimen. In the 2nd phase this 1st part of the specimen was introduced into a mold of a total height of $160 \mathrm{~mm}$ in order to allow the casting of the second part of the specimen.

\subsubsection{Implementation of the crack width, chloride immersion and electrochemical monitoring}

The target crack width was installed on the specimens after 28 days of curing and before they have been submitted to immersion in $3.5 \%$ $\mathrm{NaCl}$ solution.
The following procedure was followed for assuring the target crack width with the highest accuracy as possible:

i) The specimen was installed in a supporting system capable of assuring simple support conditions for the specimen. A pantograph was installed on the specimen in order to amplify (five times) the crack opening measured at the fiber level. A high precision mechanical dial gauge of $0.001 \mathrm{~mm}$ accuracy was used to measure the crack width recorded by the pantograph. The metal pieces of these devices that will be in contact with the solution were sealed with varnish in order not to influence the corrosion process of the fiber.

ii) The specimen fixed on the supporting system and including the pantograph was then installed into the immersion tank.

iii) The load application system represented in Fig. 6 was used. It consists of a lever system that can transfer to the specimen the necessary static load to assure the target crack width measured by the mechanical dial gauge installed in the pantograph. This force was kept constant during the immersion period.

After the target crack width was assured, the specimens were subjected to 10 days of immersion in $3.5 \% \mathrm{NaCl}$ solution in the tank (Fig. 6). The purpose of this immersion was to accelerate the process of corrosion of steel fibers, simulating a marine environment.

During the immersion period, the fiber behavior within the specimen was monitored by electrochemical measurements, including the testing of open circuit corrosion potential $\left(E_{O C P}\right)$. The electrochemical cell used for this purpose was the one described in Section 3.2.1 (Fig. 6).

\subsubsection{Fiber pullout test}

After the period proposed for maintaining the specimens immersed has been concluded, these specimens were submitted to fiber pullout tests. The fiber pullout was performed under the four-point load bending test configuration represented in Fig. 7. The tests were executed with a servo-controlled equipment under external displacement control, using for this purpose the signal of the linear variable displacement transducer (LVDT) that measures the midspan deflection of the specimen, by imposing a displacement rate of $0.001 \mathrm{~mm} / \mathrm{s}$. The applied

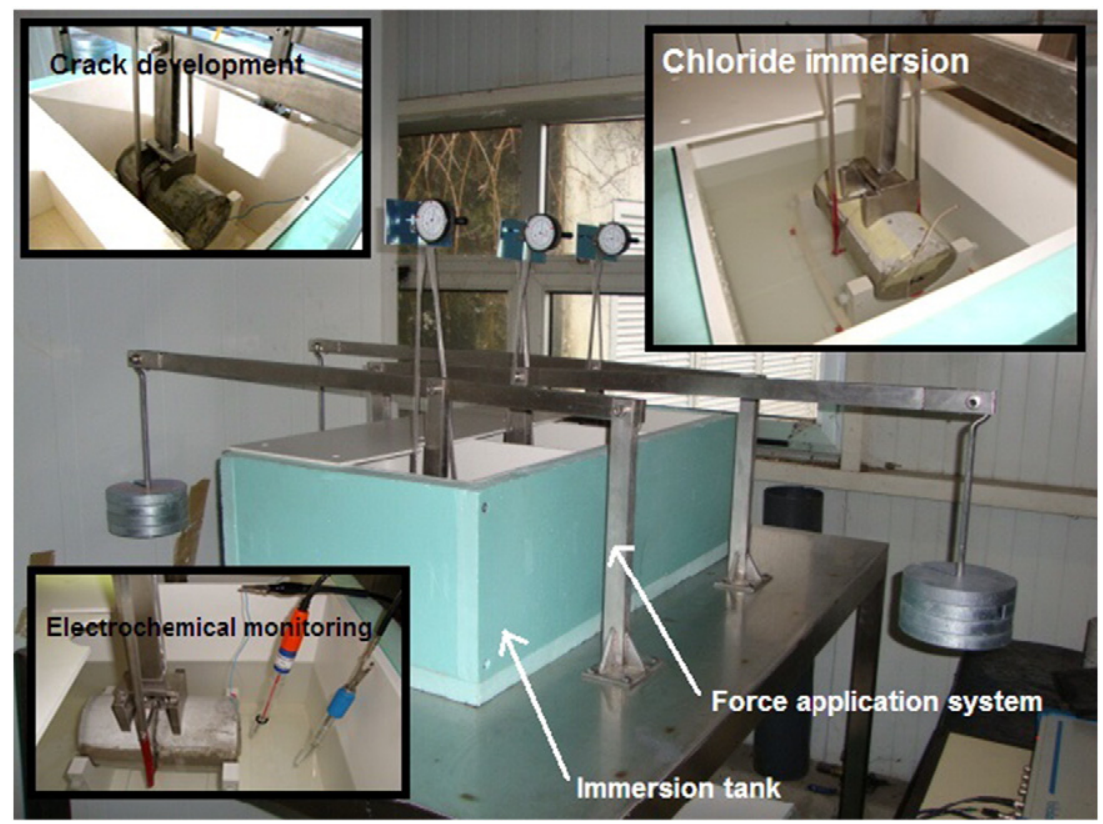

Fig. 6. Chloride immersion of cracked specimens under tension. 


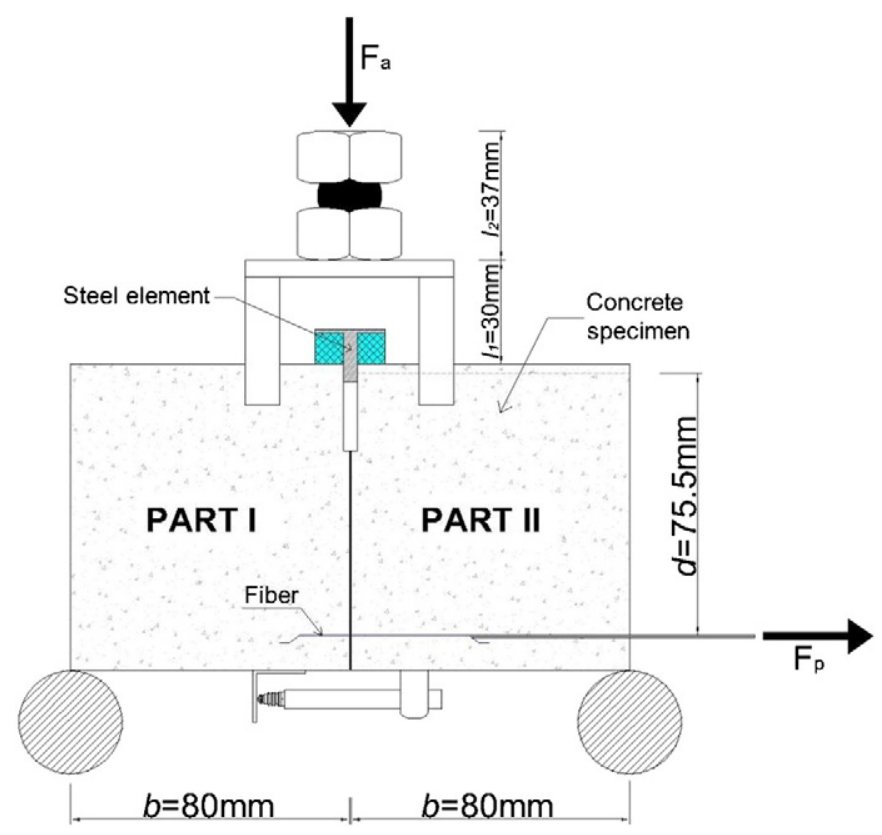

Fig. 7. Configuration of the steel fiber pullout bending test.

load was measured using a load cell of $50 \mathrm{kN}$ capacity and $250 \mathrm{~N}$ accuracy. The crack width was recorded at the crack mouth by using an LVDT mounted on the specimen in the alignment of its bottom generatrix, orthogonal to the pseudo-crack surface (Fig. 7). Due to the statically determinate character of this test, the fiber pullout force, $F_{p}$, can be obtained from the following equation (Fig. 7):

$\frac{F_{a}}{2} \times b=F_{p} \times d$

where $F_{a}$ is the applied load, $b$ is the distance from the specimen's support to the midspan ( $80 \mathrm{~mm})$, and $d$ is the distance from the fiber to the top generatrix of the specimen $(75.5 \mathrm{~mm})$.

A steel element was installed in the top part of the pseudo-fracture surface in order to transmit the compressive force through a welldefined contact area of the two parts of the specimen (Fig. 7). The slip in the fiber was obtained based on the displacement read in the LVDT and taking into account the relative position between the fiber and

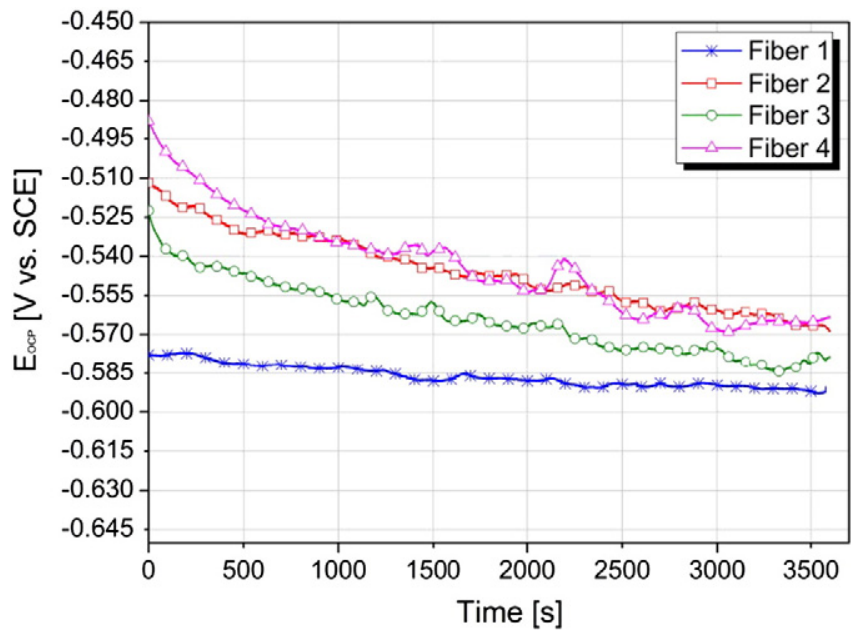

Fig. 8. Evolution of $E_{O C P}$ along the fiber over $1 \mathrm{~h}$ of immersion - series I.

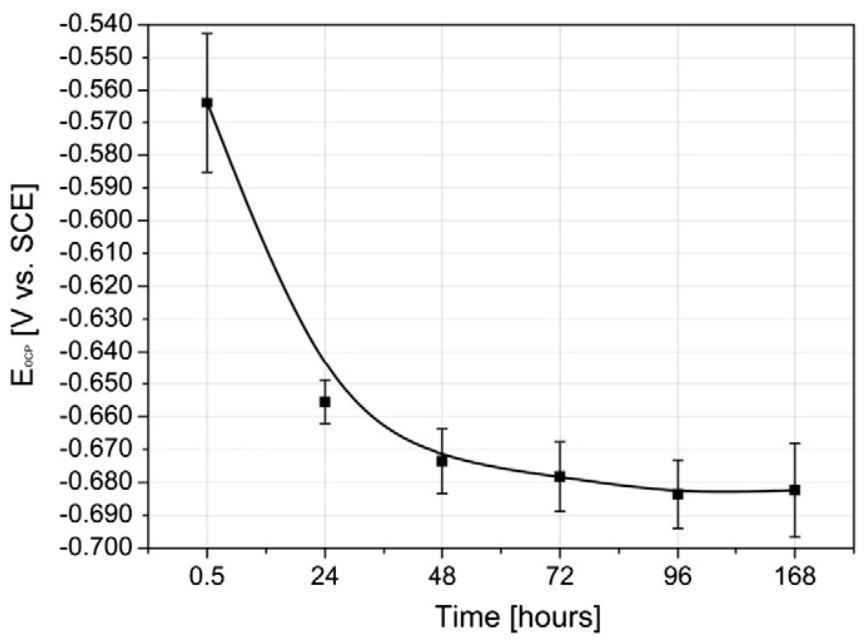

Fig. 9. Evolution of $E_{O C P}$ along the fiber over 7 days of immersion - series III.

the axis of the LVDT, applying a geometric transformation law supported on the principle that two rigid bodies which form the specimen rotate around the contact point of the aforementioned steel element. It was also assumed that the crack width recorded according to this procedure is a realistic approach of the fiber slip.

\section{Results and discussion}

\subsection{Characterization of fiber corrosion by electrochemical tests}

Figs. 8 and 9 show the results obtained in test series I and III in terms of $E_{O C P}$ versus time. It is observed that in series I, at about $60 \mathrm{~min}$, an approximately constant corrosion potential was attained in the fibers ($563 \mathrm{mV}$ to $-590 \mathrm{mV}$ ). In series III the corrosion potential has decreased and stabilized after 4 days ( $96 \mathrm{~h}$ ) of immersion.

According to the electrochemical potential monitoring test, it was found that $E_{O C P}$ decreases by increasing the immersion period of time of the fiber in the solution of $3.5 \% \mathrm{NaCl}$ (from about -540 to approximately $-700 \mathrm{mV}$ ), meaning that there is an increase of the tendency of the fibers to corrode.

According to ASTM C876 [27], the potential measurements with reference to saturated calomel electrode (SCE) can be used to assess the corrosion probability of a steel bar, and a probability of corrosion higher than $90 \%$ is indicated when potential is less than $-276 \mathrm{mV}$. Assuming this recommendation is also valid for steel fibers, and considering that

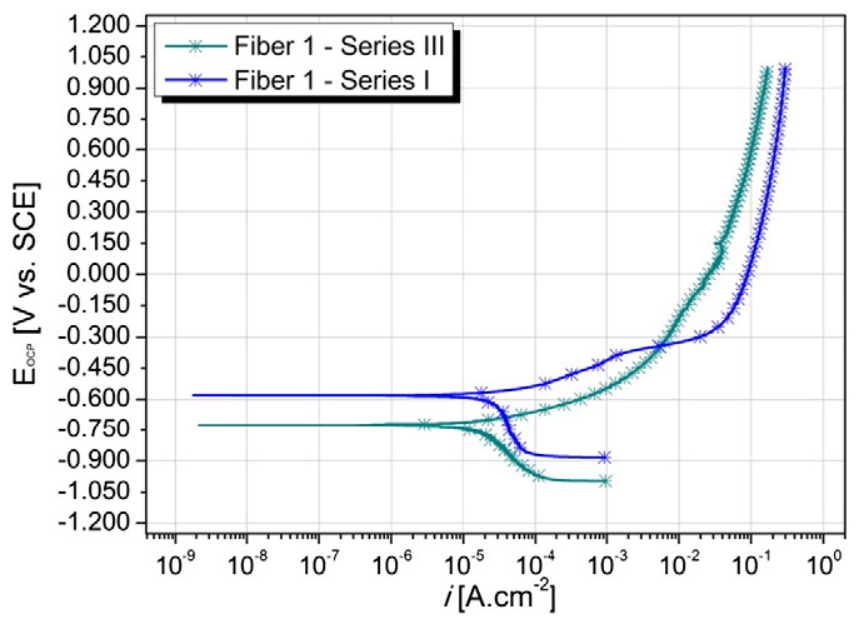

Fig. 10. Potentiodynamic polarization curves in fiber 1 - series I and III 
Table 5

Results obtained in the potentiodynamic polarization tests of series I and III.

\begin{tabular}{lllll}
\hline & & $E_{i=0}(\mathrm{mV})$ & $i_{\text {corr }}\left(\mu \mathrm{A} / \mathrm{cm}^{2}\right)$ & $R_{p}\left(\mathrm{k} \Omega / \mathrm{cm}^{2}\right)$ \\
\hline \multirow{2}{*}{ Series I } & Average \pm SD & $-573.5 \pm 7.5$ & $10.933 \pm 6.490$ & $0.871 \pm 0.255$ \\
& CoV $(\%)$ & 1.31 & 59.37 & 29.29 \\
Series III & Average \pm SD & $-711.3 \pm 15.5$ & $9.659 \pm 1.082$ & $5.569 \pm 1.416$ \\
& CoV $(\%)$ & 2.19 & 11.20 & 25.43 \\
\hline
\end{tabular}

$E_{O C P}$ lower than $-276 \mathrm{mV}$ was obtained, it can be concluded that the probability of fibers to corrode is greater than $90 \%$ when immersed in chloride solution.

Fig. 10 shows the polarization curves obtained for fiber 1 in test series I and III. The three remaining fibers showed similar polarization curves.

Table 5 shows the values of $i_{\text {corr }}$ and $R_{p}$ obtained in potentiodynamic polarization tests from series I and III. The coefficients of variation of the potentiodynamic polarization results were very high, and $R_{p}$ was quite different in the two series. For this reason it was decided to perform linear polarization tests, since these tests are carried out within a smaller range of potential sweep, and at a lower scan speed.

Fig. 11 shows the polarization curves obtained for fiber 2 in test series IV and V. Similar polarization curves were obtained with the other three fibers.

Table 6 shows the values of $i_{\text {corr }}$ and $R_{p}$ obtained in linear polarization tests of series IV and V.

For the evaluation of results in terms of corrosion current density (corrosion rate), it was adopted the criterion proposed by Alonso and Andrade [28], and González et al. [29]. According to this criterion, corrosion is active for values greater than $0.2 \mu \mathrm{A} / \mathrm{cm}^{2}$, which indicates that the tested fibers have a high risk of corrosion. The values of the polarization resistance, $R_{p}$, also confirm this risk, since the results are fairly low. From the linear polarization technique it was found that both the corrosion current density, $i_{\text {corr }}$, and the polarization resistance, $R_{p}$, have varied significantly with the immersion time.

Table 7 shows the results of weight loss of the fibers after test series I, II, IV and V. The weight loss of the fibers was larger in series I due to the execution of the potentiodynamic polarization test, where anodic applied potentials induced higher dissolution rates. Since in series II the fibers were only immersed for 7 days, the loss of fiber cross-section due to corrosion was insignificant. In series where linear polarization tests were executed (IV and V) the fiber weight loss was only a little bit higher than in series II because the induced potential was only $30 \mathrm{mV}$ lesser than the $E_{O C P}$.

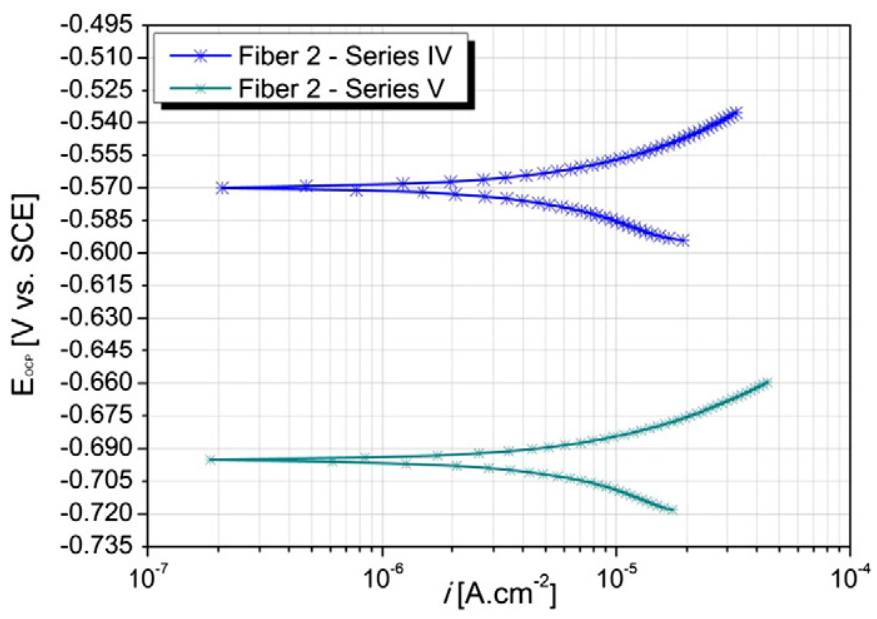

Fig. 11. Linear polarization curves in fiber 2 - series IV and V.
Table 6

Results obtained in the linear polarization tests of series IV and V.

\begin{tabular}{lllll}
\hline & $E_{i=0}(\mathrm{mV})$ & $i_{\text {corr }}\left(\mu \mathrm{A} / \mathrm{cm}^{2}\right)$ & $R_{p}\left(\mathrm{k} \Omega / \mathrm{cm}^{2}\right)$ \\
\hline \multirow{2}{*}{ Series IV } & Average \pm SD & $-566.5 \pm 4.5$ & $1.383 \pm 0.123$ & $1.588 \pm 0.140$ \\
& CoV $(\%)$ & 0.80 & 8.93 & 8.83 \\
Series V & Average \pm SD & $-677.5 \pm 21.7$ & $1.207 \pm 0.047$ & $1.378 \pm 0.049$ \\
& CoV $(\%)$ & 3.20 & 3.88 & 3.57 \\
\hline
\end{tabular}

\subsection{SEM fiber analysis}

After the electrochemical tests had been concluded, a scanning electron microscope (SEM) was performed with some tested fibers to analyze the influence of corrosion in terms of surface configuration. These observations were made in an FEI Nova 200 Field Emission Gun Scanning Electron Microscope (FEG-SEM) equipped with EDAX, Energy Dispersive X-Ray Spectroscopy (EDS), which integrates a system for microanalysis by X-ray and diffraction pattern analysis of backscattered electrons. Fig. 12 includes SEM micrographs of surface configuration of non-corroded and corroded steel fibers.

The micrograph presented in Fig. 12b shows that the corrosion is generalized in all fiber surface, forming a homogeneous film of iron oxides. The decrease in thickness of the fiber becomes evident (ca. 22\% reduction). Fig. 12d evidences the atomic contrast by backscattered electrons of chemical elements presented in the corrosive products. Through these micrographs, a chemical analysis was carried out to identify these elements. In zones Z1 and Z2 (Fig. 12d), the main chemical elements identified were carbon, $\mathrm{C}$, oxygen, $\mathrm{O}$, and iron, Fe. The elements in largest atomic percentage were iron (41.96\% in Z1 and $79.32 \%$ in Z2) and oxygen (49.38\% in Z1). These elements are the result of the corrosion process and when combined form iron oxides in higher concentration in the zone $\mathrm{Z} 1$ due to the limited presence of oxygen in the zone $\mathrm{Z} 2$ (8.45\%).

\subsection{Pullout behavior of corroded steel fibers}

Fig. 13 shows the variation of $E_{O C P}$ on steel fibers during the immersion period of time of the specimens with the following crack width values: $0.5,0.3,0.1 \mathrm{~mm}$ and $0.0 \mathrm{~mm}$. It is observed that $E_{O C P}$ has decreased with the increase of crack width, which means that the higher the crack width, the greater the possibility of the fiber to corrode. Considering the critical value of $E_{O C P}$ for high corrosion probability proposed by ASTM C876, and for the environmental conditions adopted in the present work, it seems that for a crack width less than $0.1 \mathrm{~mm}$ steel fibers are not susceptible to corrosion. It was also observed that the standard deviation (SD) of the measurements has decreased with the increase of crack width, probably due to the increase of fiber surface area in direct contact with the solution.

Fig. 14 shows the appearance of fibers after the execution of fiber pullout tests, being visible that fiber corrosion has increased with crack width. This corrosion process was extended to the full fiber embedment length. This shows that in the cracked specimens, the

Table 7

Loss of fiber weight during the tests (\%).

\begin{tabular}{lcccc}
\hline & Series I & Series II & Series IV & Series V \\
\hline Fiber 1 & 30.40 & 0.23 & 0.39 & 0.94 \\
Fiber 2 & 29.66 & 0.33 & 0.48 & 0.45 \\
Fiber 3 & 24.40 & 0.46 & 0.49 & 0.55 \\
Fiber 4 & 21.41 & 0.36 & 0.64 & 0.81 \\
Average & $\mathbf{2 6 . 4 7}$ & $\mathbf{0 . 3 4}$ & $\mathbf{0 . 5 0}$ & $\mathbf{0 . 6 9}$ \\
Standard deviation & 4.30 & 0.09 & 0.11 & 0.23 \\
CoV (\%) & 16.25 & 27.26 & 20.99 & 32.79
\end{tabular}


(a)

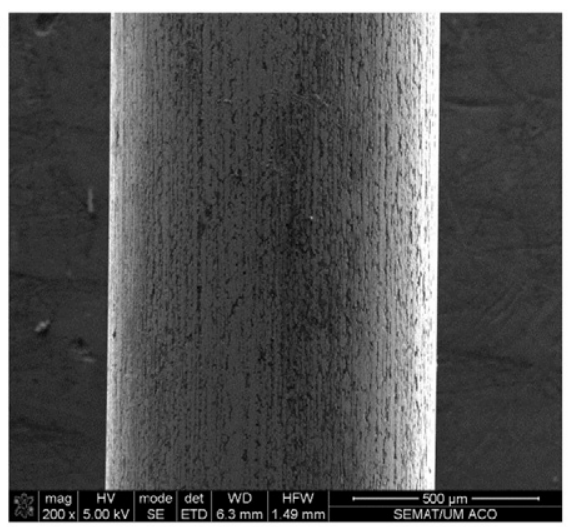

(c)

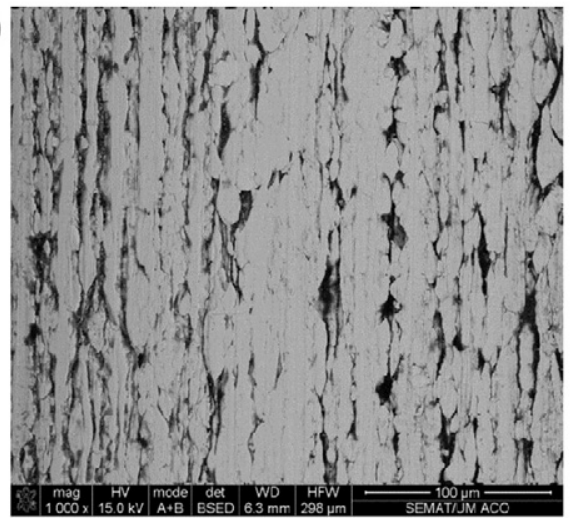

(b)

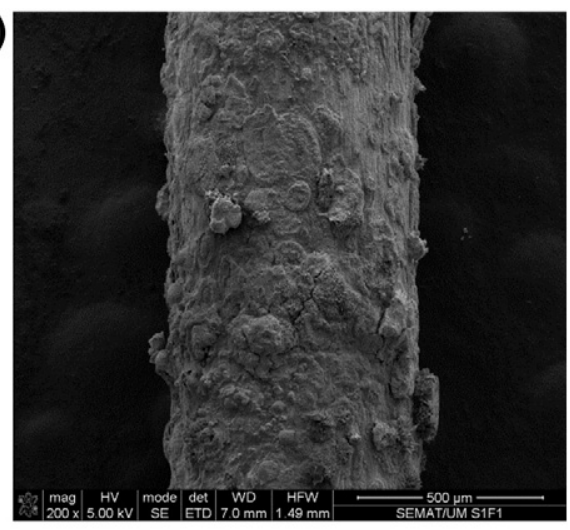

(d)

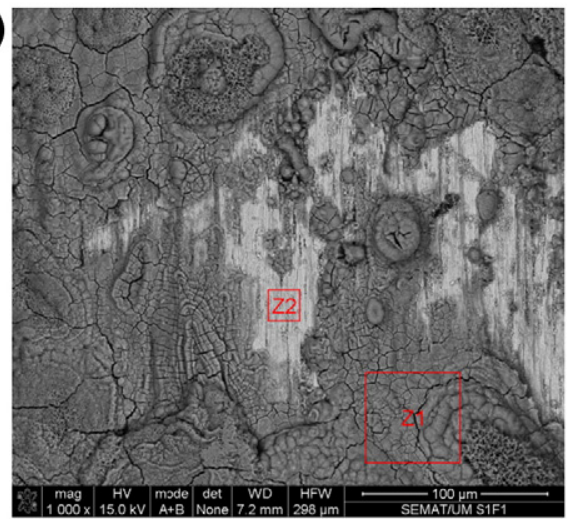

Fig. 12. SEM micrographs of the surface of steel fibers. (a) (c) Without corrosion; (b) (d) with corrosion - fiber 1 series I.

chlorides reach the entire surface of the fiber through the crack and due to concrete absorption, exceeding critical chloride content of the cementitious matrix in the fiber's neighborhood causing its depassivation and the consequent corrosion. Fig. 14b shows that in the uncracked specimens the critical chloride content was not exceeded and fibers were not affected by corrosion phenomena, keeping passivated within the matrix.

Fig. 15 presents the average curves of three tests showing the relation between the pullout force and the loaded end slip obtained on the fiber pullout tests. These tests were carried out on cracked concrete specimens made with the different crack widths considered in the present study. The obtained results evidence the occurrence of an increase of the pullout strength with the crack width. This can be

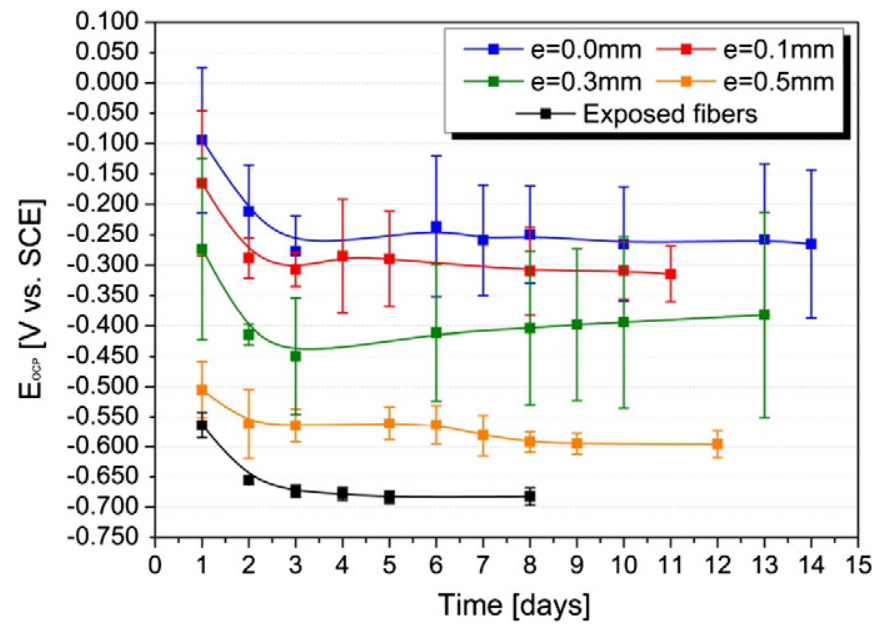

Fig. 13. Variation of the $E_{O C P}$ on steel fibers during the immersion period of time of the specimens with different crack widths. explained by the increase of the fiber surface roughness due to the formation products from corrosion, causing an increase of sliding resistance of the fiber.

The shape of the curves in Fig. 15 shows some differences from that obtained in direct fiber pullout tests [9], particularly a higher residual resistance in the post peak behavior. During the pullout bending test, the opening process of the pseudo-crack introduces some deviation to the initial orthogonality between the fiber and the surface of these cracks that increases with the crack opening. Due to this deviation the concrete surrounding the fiber, in a region close to the fiber-loaded end slip, applies normal stresses to the fiber, which increases the resistance to the fiber sliding. This mechanism is currently designated by snubbing effect [30]. This effect is due to the tendency of the fiber to be aligned with the pullout load direction. For the inclined fibers, the surrounding concrete nearby the crack offers resistance to the aforementioned fiber alignment tendency, originating a stress field in the fiber in this zone composed by normal and shear stress components. Due to a type of Mohr-Coulomb effect in the zone the normal stresses increase the pullout force inducing an increase in the residual strength of the fiber pullout [29].

\section{Conclusions}

Based on the results obtained from electrochemical tests, SEM fiber analysis and fiber pullout tests, the following observations can be pointed out:

- Based on open circuit potential $\left(E_{O C P}\right)$ measurements, the corrosion probability of steel fibers immersed in a $3.5 \% \mathrm{NaCl}$ solution is higher than $90 \%$;

- The high values of corrosion current density, $i_{\text {corr }}$, and the small values of polarization resistance, $R_{p}$, obtained in potentiodynamic and linear polarization tests indicated that the steel fibers have a high risk of corrosion in a chloride environment; 
(a)

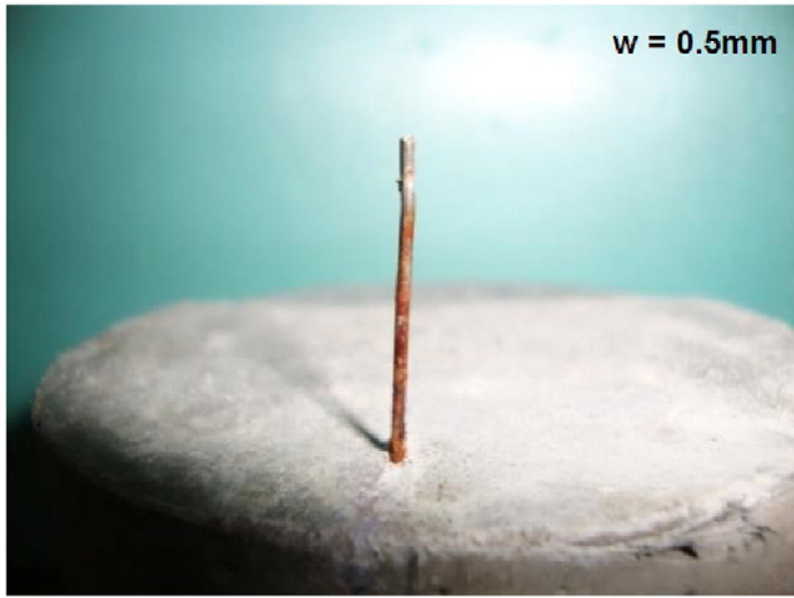

(b)

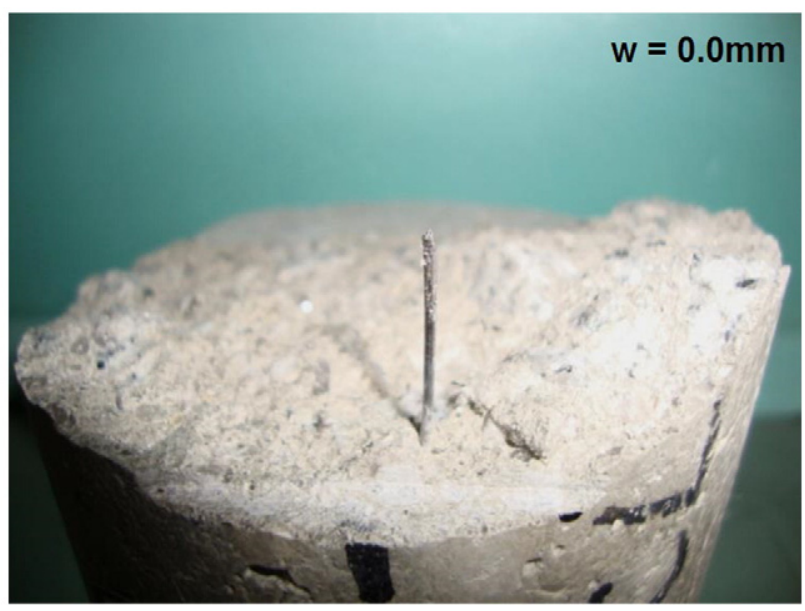

Fig. 14. Appearance of the fibers after pullout tests.

- The SEM analysis of corroded fibers has shown that corrosion was uniform on the entire fiber surface, and the main corrosion products were iron oxides;

- The susceptibility to uniform attack corrosion over the exposed surface of steel fibers crossing a pseudo-crack in SCC increases with the crack width;

- The fiber pullout strength in cracked SCC, after 10 days of immersion in $3.5 \% \mathrm{NaCl}$ solution, increased with the crack width due to the

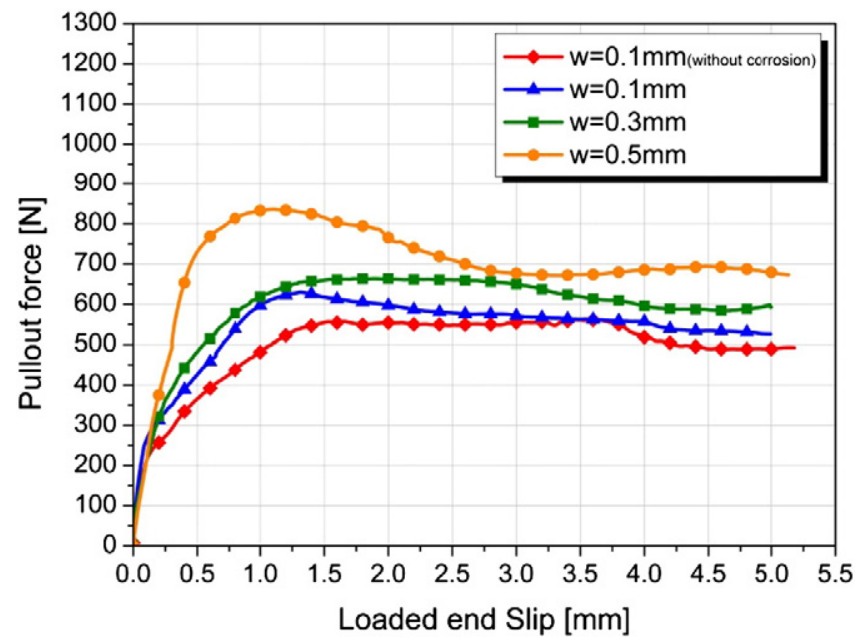

Fig. 15. Average fiber pullout load-slip curves in SCC specimens of different crack widths. increase of fiber surface roughness caused by corrosion products, which improved the interfacial bond fiber/cementitious matrix;

- The relatively high residual pullout strength in the final phase of the fiber pullout test is caused by the pullout bending character of the adopted test that increases the fiber/matrix shear friction with the crack opening process (snubbing effect).

\section{Acknowledgments}

The study reported in this paper is part of the research project QREN number 5387, LEGOUSE - Development of cost competitive pre-fabricated modular buildings, involving the Companies Mota-Engil, CiviTest, the ISISE/University of Minho and PIEP. The authors wish to acknowledge the support provided by Maccaferri and Radmix for supplying the fibers, Sika for the superplasticizer, Secil for the cement and Omya Comital for the limestone filler. The first author acknowledges the research grant under this project.

\section{References}

[1] J. Barros, L. Lourenço, F. Soltanzadeh, and M. Taheri, (2014), Steel fibre reinforced concrete for elements failing in bending and in shear, European Journal of Environmental and Civil Engineering, V.18(1) (2013), pp. 33-65 (http://dx.doi.org/10.1080/ 19648189.2013.842937).

[2] C. Frazão, A. Camões, J. Barros, D. Gonçalves, Durability of steel fiber reinforced selfcompacting concrete, Constr. Build. Mater. 80 (2015) 155-166, http://dx.doi.org/10. 1016/j.conbuildmat.2015.01.061.

[3] C. Aldea, S. Shah, Durability enhancements of cracked concrete by fibers, ACI Spec. Publ. 276 (2011) 1-14.

[4] A. Singh, D. Singhal, Permeability of steel fibre reinforced concrete influence of fibre parameters, Proc. Eng. 14 (2011) 2823-2829.

[5] A. Solgaard, A. Kuter, C. Edvardsen, H. Stang, M. Geiker, Durability aspects of steel fibre reinforced concrete in civil infrastructure, Proc. 2nd International Symposium on Service Life Design for Infrastructure, RILEM Publications, Delft, The Netherlands, Oct. 4-6 2010.

[6] S. Balouch, J. Forth, J. Granju, Surface corrosion of steel fibre reinforced concrete, Cem. Concr. Res. 40 (2010) 410-414.

[7] C. Berrocal, K. Lundgren, I. LÖfgren, Influence of steel fibres on corrosion of reinforcement in concrete in chloride environments: A review, In: Proceedings of International Conference:FC2013-Fiber Concrete 2013, 12th-13th September 2013, (Prague, Czech Republic)

[8] H. Sadeghi-Pouya, E. Ganjian, P. Claisse, K. Muthuramalingam, Corrosion durability of high performance steel fibre reinforced concrete, Proceedings of 3rd International Conference on Sustainable Construction Materials and Technologies, Japan Concrete Institute, Kyoto, Japan, Aug. 2013.

[9] J. Granju, S. Balouch, Corrosion of steel fibre reinforced concrete from the cracks, Cem. Concr. Res. 35 (2005) 573-577.

[10] ACI 544.5R-10, Report on the Physical Properties and Durability of Fiber Reinforced Concrete, ACI Committee, 5442010.

[11] X. Shi, N. Xie, K. Fortune, J. Gong, Durability of steel reinforced concrete in chloride environments: an overview, Constr. Build. Mater. 30 (2012) 125-138.

[12] I. Yoon, Chloride Penetration through Cracks in High-Performance Concrete and Surface Treatment System for Crack Healing, Advances in Materials Science and Engineering, V, Hindawi Publishing Corporation, 2012 (Article ID 294571, 8 pp.).

[13] E. Nordstrom, Durability of Sprayed Concrete-Steel Fibre Corrosion in Cracks, Doctoral Thesis Department of Civil and Environmental Engineering, Division of Structural Engineering, Luleå University of Technology, 2005.

[14] S. Saojeng, L. Weiting, Effects of silica fume and steel fiber on chloride ion penetration and corrosion behavior of cement-based composites, J. Wuhan Univ. Technol. Mater. Sci. Ed. 28 (2) (2013).

[15] V. Corinaldesi, G. Moriconi, Durable fiber reinforced self-compacting concrete, Cem. Concr. Res. 34 (2004) 249-254.

[16] V. Cunha, J. Barros, J. Sena Cruz, Pullout behaviour of steel fibres in self-compacting concrete, J. Mater. Civ. Eng. 22 (1) (2010) 1-9.

[17] V. Cunha, J. Barros, J. Sena-Cruz, An integral approach for modelling the tensile behaviour of steel fibre reinforced self-compacting concrete, Cem. Concr. Res. 41 (2011) 64-76.

[18] D. Dupond, Modelling and Experimental Validation of the Constitutive Law and Cracking Behaviour of Fiber Reinforced ConcreteDoctoral Thesis Department of Civil Engineering, Catholic University of Leuven, Belgium, 2003.

[19] A. Bentur, S. Mindess, Fibre Reinforced Cementitious Composites, 2nd edition Francis \& Taylor, UK, 2007

[20] P. Robins, S. Austin, P. Jones, Pull-out behavior of hooked steel fibres, Technical Reports, Materials and Structures, 35 2002, pp. 434-442.

[21] A. Pompo, P.R. Stupak, L. Nicolais, B. Marchese, Analysis of steel fibre pull-out from a cement matrix using video photography, Cem. Concr. Compos. 18 (1996) 3-8.

[22] J. Barros, E. Pereira, S. Santos, Lightweight panels of steel fibre reinforced selfcompacting concrete, J. Mater. Civ. Eng. 19 (4) (2007) 295-304. 
[23] D. Enos, The Potentiodynamic Polarization Scan, Technical Report 33, Center of Electrochemical Science \& Engineering, Department of Materials Science \& Engineering, University of Virginia, Charlottesville, VA, 1997.

[24] ASTM G59-97, Standard Test Method for Conducting Potentiodynamic Polarization Resistance Measurements, ASTM International, 2009 1-4.

[25] S. Wolynec, Electrochemical Techniques in Corrosion, Edusp - Publisher of University of São Paulo, São Paulo, Brasil, 2003 (Portuguese).

[26] D21V032, VoltaLab systems with VoltaMaster 4, User's Manual (English), HACH LANGE GmbH, Germany, 2013.

[27] ASTM C876-09, Standard Test Method for Corrosion Potentials of Uncoated Reinforcing Steel in Concrete, ASTM International, 2009.
[28] C. Alonso, C. Andrade, Effect of nitride as a corrosion inhibitor in contaminated and chloride-free carbonated mortars, ACI Mater. J. 78 (2) (1990) 130-137.

[29] J. González, J. Miranda, S. Feliu, Considerations on reproducibility of potential and corrosion rate measurements in reinforced concrete, Corros. Sci. 46 (2004) 2467-2485.

[30] A. Døssland, Fibre Reinforcement in Load Carrying Concrete Structures, Doctoral Thesis Department of Structural Engineering, Faculty of Engineering Science and Technology, Norwegian University of Science and Technology, 2008. 